\title{
Article
}

\section{The Need for Ecosystem 4.0 to Support Maintenance 4.0: An Aviation Assembly Line Case}

\author{
Alessandro Giacotto ${ }^{1}\left(\mathbb{D}\right.$, , Henrique Costa Marques ${ }^{1, *} \mathbb{C}$, Eduardo Afonso Pereira Barreto ${ }^{1}$ and Alberto Martinetti ${ }^{2}$ \\ 1 Logistics Engineering Laboratory, Aeronautics Institute of Technology, \\ São José dos Campos, SP 12.228-900, Brazil; agiacott@ita.br (A.G.); barretoe@ita.br (E.A.P.B.) \\ 2 Design, Production and Management Department, University of TWENTE, \\ 7522 NN Enschede, The Netherlands; a.martinetti@utwente.nl \\ * Correspondence: hmarques@ita.br; Tel.: +55-12-3947-5763
}

Citation: Giacotto, A.; Costa Marques, H.; Pereira Barreto, E.A.; Martinetti, A. The Need for Ecosystem 4.0 to Support Maintenance 4.0: An Aviation Assembly Line Case. Appl. Sci. 2021, 11, 3333. https://doi.org/10.3390/ app11083333

Received: 12 March 2021

Accepted: 5 April 2021

Published: 8 April 2021

Publisher's Note: MDPI stays neutral with regard to jurisdictional claims in published maps and institutional affiliations.

Copyright: (c) 2021 by the authors. Licensee MDPI, Basel, Switzerland. This article is an open access article distributed under the terms and conditions of the Creative Commons Attribution (CC BY) license (https:/ / creativecommons.org/licenses/by/ $4.0 /)$.
Featured Application: The proposed prescriptive maintenance framework supports the maintenance teams in the Industry 4.0 ecosystem, enhancing the availability of diverse machinery and team capabilities.

\begin{abstract}
Manufacturing and assembling aircraft require hundreds of different machines for various process applications. The machines have different complexity and often different ages; however, they have to ensure a higher precision than other industrial fields. Recent technology advancement in maintenance approaches offers a wide range of opportunities to provide performance and availability. The paper discusses how the maintenance technologies applicable to the various machines need to be appropriately supported by a production environment, called "ecosystem", that allows their integration within the process and their synergy with the operators. (1) A background analysis of the aircraft production environment is offered. (2) A possible framework for designing a proper ecosystem 4.0 for integrating maintenance activities with design solutions and data gathering is provided. (3) A case study based on the assembly line of specific aircraft is adopted for testing the validity of the framework. (4) Finally, a discussion highlights the critical points of the research, underlying future work.
\end{abstract}

Keywords: ecosystem 4.0; maintenance 4.0; aviation; aircraft manufacturing; assembly line

\section{Introduction}

Large commercial, executive, or defence aircraft assemblers have manufacturing lines composed of many machines for various purposes. Nevertheless, human labour is still responsible for the vast majority of the assembly and finishing phases of different parts. This is partly due to the large size of aeronautical parts that require large and heavy machines, which has hampered the development of automation in the sector. More demanding than the automotive industry, the aeronautical sector also has higher precision and quality requirements, further increasing technological development for manufacturing through autonomous machines [1]. Bogue [2] mentioned that robots' use is far more limited in the aerospace industry than in the automotive sector. The most significant development of automation in the sector consists of drilling and riveting panels for wings and fuselage and transporting large parts for the assembly of aircraft wings and fuselage sections [1,3,4] Robotic cells have been used in this sector, with high availability, precision, and quality, also becoming a point of attention for producing the input for several other workshops on the assembly line [3].

The challenge in an aircraft assembly company's production line maintenance is to have different types of machinery at different maintenance paradigms. There are machines built decades ago that only have a maintenance plan (scheduled maintenance interventions) based on obsolete information. In contrast, newer machines already have predictive maintenance 
or preventive maintenance approaches in a Total Productive Maintenance (TPM) policy. Adjusting the corrective, preventive, and predictive maintenance plans to be carried out by a small group of maintainers becomes a significant challenge as the machines degrade and the degradation model is not defined. This happens due to a lack of manufacturer's information, ageing of the machinery, the absence of sensors, or a combination of them [4]. However, due to the appearance of corrective maintenance or a change in the demand for the manufacture of new aircraft, there may be a change in parameters and a need to redesign several machines maintenance plans in the line. Such a situation generates rework and, possibly, a not optimal result for the production line's production and maintenance. The loss of expected productivity and sub-optimal maintenance costs may reduce the company's revenue. A flexible plan is built each year of operation so that there is a statistical base that will support maintenance for decision-makers.

Big Data analytics and Digital Twins came to support this approach, but only monitored machines or processes may take advantage of the technique. The Digital Twins' concept is the most comprehensive in terms of using technologies aimed at Industry 4.0. The work of Qi [5] declares that the main difficulty is to establish the right technologies and tools to use the approach appropriately. The result of He [6] brings the evidence of acquiring situation awareness from digitized processes, captured data, and performed prognosis throughout the virtualized system, providing timely information to the various actors and decision-makers. Gao [7] pursues the challenge to provide an effective and efficient way to enhance productivity using Big Data Analytics, keeping the economy within the established boundaries and promoting the value-added product. In all these works, the maintenance costs are relevant and should be considered in the total cost.

This research paper seeks to identify the Industry 4.0 technologies' current opportunities to generate an "ecosystem" that facilitates information acquisition on the processes being executed and the existing assets to obtain the best possible results. It is intended to build a framework to support situational awareness to decision-makers and to suggest the optimal use of the current maintenance workforce being allocated, favouring a smooth and more extensive adoption of the prescriptive maintenance approach. Prescriptive maintenance uses the same knowledge in terms of data from predictive maintenance, integrating it with advice related to the maintenance window of opportunity and the tasks the workers need to perform. It allows generating better overall performance optimizing the allocations of resources, such as work floor surface and assets, for each task at the right moment. Therefore, the output of a prescriptive maintenance process must be a dynamic schedule of preventive maintenance according to the maintenance teams' adversities, spare parts, equipment availability, and tools in the identified maintenance window of opportunity, and the correct maintenance procedure manual. The primary purpose is to keep the machinery's high availability during the expected time of its utilization, given the production demand at the manufacture and assembly lines. The work in Choubey [8] brought the evidence that prescriptive maintenance is still in its infancy and lacks real-world implementations and lessons learned to empower its usage on a large scale. Marques [9] established the Smart Prescriptive Maintenance Framework (SPMF) utilized in the present work to provide a path to prescriptive maintenance implementation in any industry using the ecosystem 4.0 capabilities.

Considering that the window of opportunity's prediction is the foremost approach to optimise the entire maintenance process, the present study identified possible techniques to establish this purpose. Several methods are being utilised in literature to predict the window of opportunity based on production planning and product quality. The work in Shamsaei [10] exposed how limiting the problem size could be depending on the solver and algorithmic approach being used. The authors managed to increase the problems' size using a hybrid capacity planning approach based on non-cyclic maintenance (NCMP) and cyclic maintenance (CMP), showing that the solution could have exponential possibilities. The authors utilized a Mixed-Integer Programming (MIP) solver to such problems and could find the solution in a reasonable time, but they did not work with multiple 
machines. Matyas [11] proposed a procedural approach using multivariate data analysis and simulation tools to identify data correlations and real-time failures and implement it in a real-world scenario in the automotive manufacturing industry. The authors considered a scenario of production planning with multiple machines' maintenance planning but did not consider a dynamic production environment. Koops [12] presented an analytical process for prescriptive maintenance based on data analysis and Monte Carlo simulation; however, no discussion was mentioned about ecosystem 4.0 as an enabler. Kerin [13] discussed in depth the enablers and main paradigms of the Industry 4.0 remanufacturing and proposed framework but did not present simulations or applications in the prescriptive maintenance field. Similarly, Navas [14] presented a smart maintenance framework, discussed the technological enablers, and asserted that maintenance 4.0 is an uncontestable trend but did not present a simulation or case study.

To capture the dynamicity of the environment is necessary to apply the Industrial Internet of Things (IIoT) and understand the patterns in the captured data as already declared in Gao's work [7]. IIoT comprehends sensors that provide data to support Big Data Analytics and the pattern recognition effort that uses machine learning algorithms as presented in the work of Doce [15]. Diez's work [16] exposed the main contributions to state-of-the-art descriptive, predictive and prescriptive maintenance using optimization and machine learning algorithms. The authors proposed trends and perspectives about prescriptive maintenance, including metrics variability and conflicting objectives such as productivity and reliability that may affect the design of efficient solvers for problem resolution. Based on the considerations about the ecosystem 4.0 opportunity to contribute to the prescriptive maintenance approach and the trends exposed, the present work provides a novel framework that integrates different techniques, combining MIP and a real world dynamic production environment case study as the main contribution to the prescriptive maintenance implementation.

\section{Materials and Methods}

The Smart Prescriptive Maintenance Framework (SPMF), introduced in Marques [9], was developed and tested on a study case to support the introduction of prescriptive maintenance. The present work assembly line presents complex production systems (robots and other equipment), a specific operating environment that provides production requirements or production levels, and a well-defined maintenance capability constituted by maintenance labour, tooling, tribal knowledge and infrastructure suitable for the implementation of the SPMF.

The SPMF is built on three domains of interest captured through data fusion methodologies and integrated by artificial intelligence approaches. The SPMF's domains of interest are:

1. the system's Reliability, Availability, Maintainability and Safety (RAMS) factors;

2. the operating environment in which the system is being deployed;

3. the organization's maintenance capabilities [9].

As restrictions treated in de Mello [3], time is considered during the maintenance schedule that cannot be postponed or anticipated. Cost is also considered, although indirectly, in the restriction that imposes a limit on the available maintenance man-hours and by the objective function, which aims to minimize the maintenance man-hours spent, as presented in Section 3.2.

According to Marques [9], although the SPMF was conceived to implement the prescriptive maintenance on a commercial jet fleet, it can be generalized and used to support any complex system. Each domain was selected because it contains essential system information and performance requirements that feed the prescriptive maintenance framework algorithm, so the best group of maintenance actions is defined.

Figure 1 presents the framework which unifies ecosystem 4.0 and the SPMF applied to the aviation assembly line. The bottom right box shows the idealized assembly line 
constituted by robots, tools, equipment, workers, and logistics activities. The whole production process and resources are scheduled by the product demand [17].

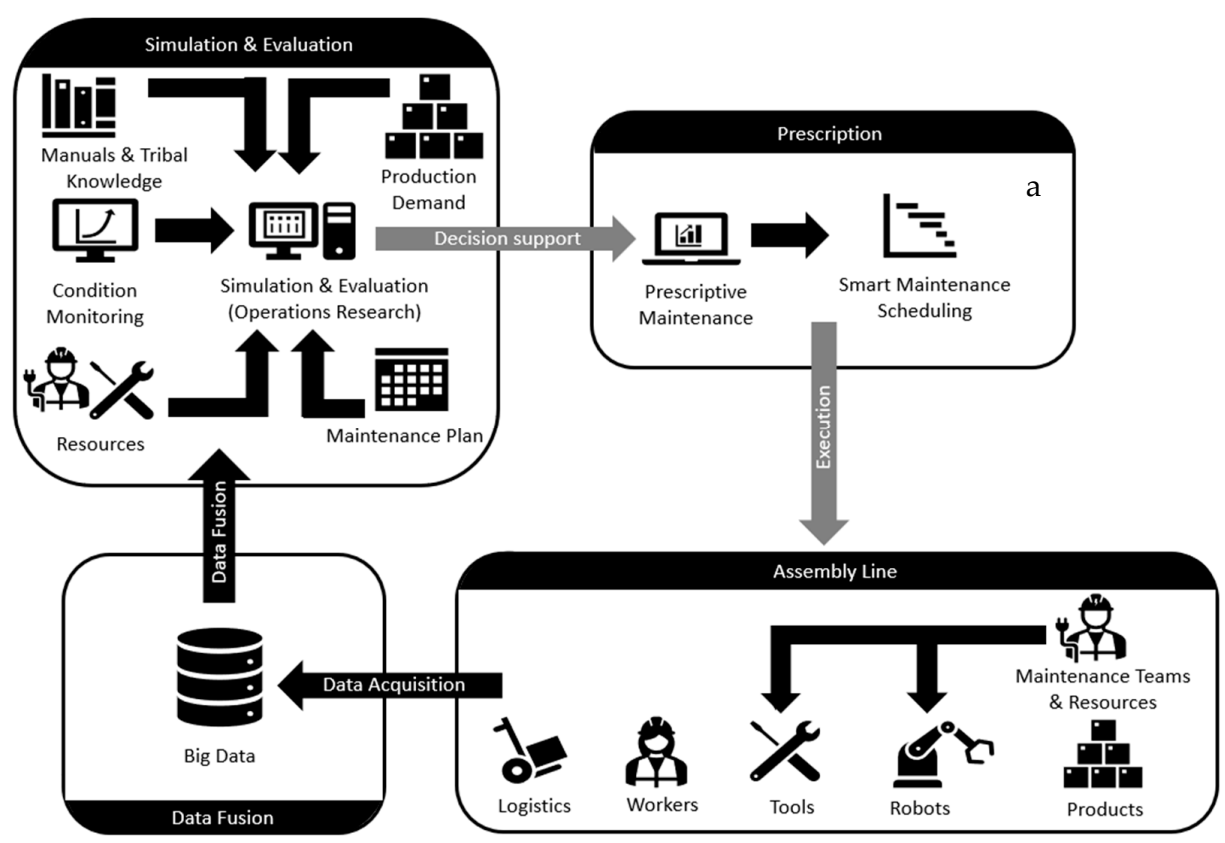

Figure 1. SPMF for integrating different Ecosystem 4.0 in the assembly line.

The framework was built considering the three SPMF's domains previously mentioned:

1. RAMS information is represented by the technical publications, manuals, specs, maintenance plan, and the data gathered from the condition monitoring;

2. The operating environment and requirements are essentially defined by the production demand, robots, tools, and workforce; and

3. The organization's maintenance capabilities are described by the maintenance resources such as tools, labour available, and maintenance tribal knowledge.

Wired or wireless networks and sensors continuously collect temperature, position, humidity, vibration sensors, Radio Frequency Identification (RFID) and internal processes such as built-in-test capabilities, performance, health status and equipment usage. The acquired data sets are successively stored in a centralized big data warehouse. The information is standardized and structured for the simulation and evaluation stage to prescribe and schedule maintenance tasks in real time and keep the assembly line functioning at the required performance through data fusion.

The simulation process aims to develop the best maintenance course of action to maximize the Overall Equipment Effectiveness (OEE) and minimize maintenance manhours while ensuring production level.

In the simulation and evaluation stage, all the knowledge-base, parameters, system characteristics, and requirements are considered to generate prescriptive maintenance recommendations.

The information considered by the simulation algorithm within the SPMF's framework is listed below:

- Maintenance manual and maintenance team's "tribal" knowledge;

- Equipment condition monitoring to support Prognostics and Health Management, including Remaining Useful Life (RUL) evaluation;

- Available resources such as maintenance labour and tools;

- The maintenance plan, including tasks and their interval; and

- Production demand. 
The methodology adopted for the simulation is the Mixed-Integer Linear Programming or Mixed-Integer Programming (MIP), well known in the Operations Research field. The choice of MIP is related to its intrinsic characteristic to optimize a complex organization's operational efficiency while considering demands, capacity and other business rules as a constraint of the system. Shamsaei [10] mentioned that MIP is simpler, faster and more effective than other methodologies such as heuristics and meta-heuristics for industrial systems problems, like the proposed case study. This approach is also strengthened by Schrotenboer [18], who demonstrated that MIP could be successfully used to optimize maintenance equipment under operational uncertainties.

In the top-right box, identified with the letter "a", in Figure 1, a real-time updated prescriptive maintenance plan is presented to the maintenance engineer who takes the final decision about how to maintain the assembly line. This decision support system is often constituted by a "smart" maintenance scheduling that provides, also in real time and in Gantt form, a dynamic maintenance plan for each piece of equipment.

The plan is then executed on the assembly line by the maintenance team. In a feedback loop form, the OEE parameters and maintenance labour performance are measured. The system assesses its performance, continuously improves the algorithm, and adjusts parameters according to product demand and assembly resources in a non-stop, continuous improvement cycle.

\section{Case Study}

The case study's goal is to determine whether the adoption of SPMF improves OEE and decreases the maintenance man-hour of a commercial aircraft wing assembly line. The methodology to build the case study included semi-structured interviews with maintenance engineers who have been responsible for the maintenance of more than 90 machines of an aerospace manufacturer assembly line for 20 years. The field exploration helped to define parameters such as the monthly wing demand in a production rump up scenario, the number of production cells, maintenance team size, the meantime to repair (MTTR), and the maintenance strategy usually adopted. It is essential to mention that some parameters could not be collected or were not available from the field exploration, thus were identified through a literature review. The limitation arising from adopting this literature's parameters is that the data are different from the field's information. However, the magnitude of the possible incongruency does not invalidate the study since the product (aircraft wing) and the assembly line type (organized in levels) are the same observed in both scenarios: in the field and the literature. Table 1 presents the parameters collected through field exploration, the ones identified from the literature review, and both.

Table 1. Parameters' sources

\begin{tabular}{ccc}
\hline Parameter or Assembly Line Characteristics & Field Exploration & Literature \\
\hline Monthly production & $\mathrm{x}$ & \\
\hline Assembly level & $\mathrm{x}$ & {$[19]$} \\
\hline Number of robots & & {$[19]$} \\
\hline Riveting per robot, per wing & $\mathrm{x}$ & {$[20-23]$} \\
\hline Mean Time Between Failures & & {$[19]$} \\
\hline Production rate & $\mathrm{x}$ & {$[24]$} \\
\hline Robot Maintenance Class & $\mathrm{x}$ & {$[21]$} \\
\hline Robot Maintenance Strategy & $\mathrm{x}$ & \\
\hline Maintenance Tasks Types and Intervals & $\mathrm{x}$ & $\mathrm{x}$ \\
\hline Mean Time to Repair & $\mathrm{x}$ & \\
\hline Team size and expertise &
\end{tabular}




\subsection{Assembly Line Description}

The assembly line mentioned in de Mello [3] is considered and shown in Figure 2, capable of assembling a three-piece wing box as an example. This assembly operation is divided into four steps, as demonstrated in Figure 2:

1. First assembly level: parts like skins, stringers, stiffeners, and doublers are joined to form upper and lower panels, as well as spar, ribs, and bulkhead subassemblies;

2. Second assembly level: these subassemblies are joined to form left, right and centre $\mathrm{rib} / \mathrm{spar}$ grid structures;

3. Third assembly level: upper and lower panel subassemblies are joined with the rib/spar to form left, right and centre boxes;

4. Fourth assembly level: three wing boxes are joined to form the final wing.

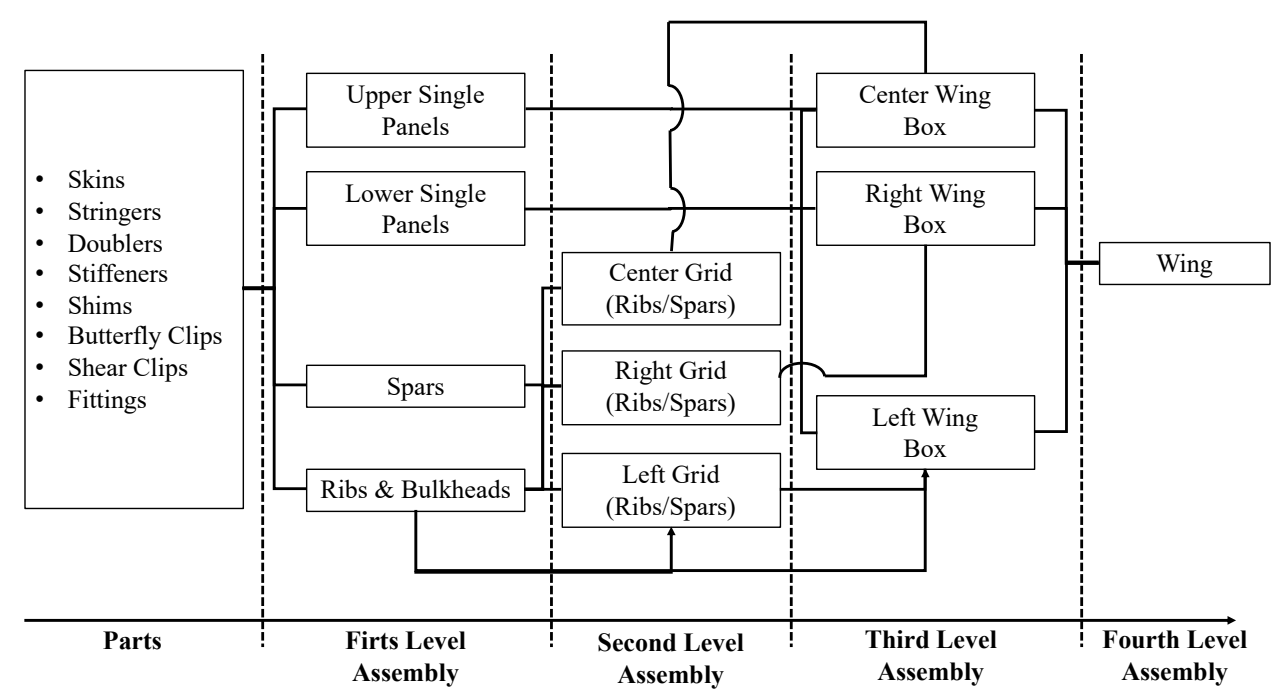

Figure 2. Wing flow assembly, adapted from Diez-Olivan [15].

As shown in Table A1 of Appendix A, 57\% of all fasteners and rivets needed to assemble the wing are used at the first level, making it easier to automatize. Joining skin panels to the grid in the third level requires $34 \%$ of all rivets and fasteners, and even though automatization here is more challenging than the first level, it is still worth it. Although the final level only requires $3 \%$ of the fasteners, the time needed to install these larger fasteners without the aid of robots would be a magnitude higher than the time required to install fasteners in first level assembly; thus, automatization is highly recommended in this level, and it was adopted for the case study analysed in this paper. The second level only requires $6 \%$ of the total rivets/fasteners. Finally, manual installation is easy and acceptable in this step, thus turning the use of robots uneconomical. As a result, the second level's assembly tasks were assumed to be manually executed in the model proposed. The line was modelled according to the parameters listed in Table A2 of Appendix A. The parameters were acquired from the semi-structured interviews during the field exploration and confirmed through the literature review, as previously presented in Table 1.

\subsection{Mathematical Model}

Given that the preventive maintenance of an assembly line is an unavoidable part of the operation, robots must be stopped for regular maintenance activities. In this regard, time spent in maintenance is unproductive, reducing the availability of KPI's in the assembly process. The aim of the proposed model is therefore to reduce this unproductive time brought on by preventive maintenance. Khatab [25] presents a similar objective function, however, focusing on the cost incurred by the labour hours. Since this paper focuses on the overall efficiency of the assembly line, the repair teams are considered to have a fixed cost to be on standby for maintenance, thus this cost is not relevant at his point. The assembly 
line described in Section 3.1 was mathematically modelled according to the parameters, variables and formulation presented below:

\section{Parameters}

I: set of maintenance activities;

$J$ : set of maintenance teams;

$R$ : set of robots;

K: set of robot types;

$T$ : total number of maintenance activities required;

$W$ : total working hours of maintenance teams in a period.

Robot_Vector: vector that lists the robot types and their position in the assembly line

Experience_Matrix: defines the $J$ teams' experience and knowledge in maintaining each of the K robot types. In alignment with the observations in the assembly line during the field exploration, it was adopted as a system of five experience levels as suggested by the International Labour Organisation [26] as explained below:

- Level 1-shallow experience: performs $25 \%$ slower than the MTTR for a team to execute the maintenance tasks;

- Level 2-low experience: performs 10\% slower than MTTR for a team to execute the maintenance tasks;

- Level 3-average experience: it takes a time equal to the MTTR to execute the maintenance task;

- Level 4-high experience: performs 10\% faster than the MTTR to execute the maintenance task; and

- Level 5-very high experience: performs $25 \%$ faster than the MTTR to execute the maintenance task.

Experience_Factor: vector that lists the experience levels used to calculate how long it takes for the team to perform a maintenance task.

Average $_{i r}$ : average time to perform maintenance task $i$ for robot $r$.

$t_{i j r}$ : the time required by team $j$ to perform maintenance activity $i$ on robot $r$.

Decision variables

$z_{i j r}$ : decision variable that assumes the value one (1) if team $j$ performs maintenance activity $i$ on robot $r$.

C: number of cancelled maintenance activities

Objective Function

$$
\min \sum_{i \in I} \sum_{j \in J} \sum_{r \in R} t_{i j r} z_{i j r}
$$

Restrictions

$$
\begin{gathered}
\sum_{j \in J} z_{i j r} \leq 1 \forall i \in I, \forall r \in R \\
\sum_{r \in R} t_{i j r} z_{i j r} \leq W \forall i \in I, \forall j \in J \\
C+\sum_{i \in I} \sum_{j \in J} \sum_{r \in R} z_{i j r}=T \\
z_{i j r} \in\{0,1\} \forall i \in I, \forall j \in J, \forall r \in R
\end{gathered}
$$

The objective function, Equation (1), aims to minimize the robot downtimes by reducing maintenance man-hours over the 15 years of operation considered. Here, $t_{i j r}$ is defined in Equation (6):

$$
\left.t_{i j r}=\text { Average }_{i r} \times \text { Experience_Factor }_{(\text {ExperinceMatrix }}, \text { RobotVector }_{r}\right)
$$

Equation (2) is a restriction that imposes that maintenance activity must only be done once by one team. Equation (3) determines that the maintenance man-hours cannot exceed the established maximum work hours of a team in a certain period, which, in this case, is 
16 man-hours/day in seven days, meaning there are a total of 112 man-hours each seven days. Variable C in Equation (4) represents the number of tasks that could not be performed because of unavailable labour. Equation (5) defines variable $z_{i j r}$ as binary, equal to 1 if maintenance $i$, for robot $r$, is performed in time $t$ and equal to 0 otherwise.

A more global parameter is used to better compare the different cases presented in this work. This parameter is the OEE that takes into account availability, performance, and quality. For all effects in this work, the performance and quality are considered constant; thus, the availability can be more efficiently compared.

Equations (7) and (8) define the measured OEE and availability for the tested cases:

$$
\begin{gathered}
\text { OEE }=\text { Availability } \times \text { Performance } \times \text { Quality } \\
\text { Availability }=\frac{\text { AvailableHours }- \text { Downtime }}{\text { AvailableHours }}
\end{gathered}
$$

Due to the scenario's structure tested in the following cases, the amount of maintenance activity hours in some periods is purposefully superior to the available labour hours. Thus, each case presents several cancelled maintenance activities in total planning. These cancelled activities are considered as downtime for the robots. Except for case 2, all cases were solved using the mixed-integer linear programming model presented previously. The system used to run the simulations was a laptop computer with 8 GB of RAM and operating system macOS Big Sur version 11.1 [27] running the open-source GUROBI solver [28] in MATLAB version R2020b [29].

\section{Introduction to the different scenarios}

Within the assembly line described in Section 3, four maintenance scenarios were modelled to evaluate how the SPMF can improve the OEE and the equipment availability over an assembly line life-cycle of 15 years. This time period was selected to include over-haul and heavy maintenance, that, according to field exploration, literature review, and historical data, happen every 12 to 15 years for the considered equipment. These four different scenarios are relevant because they model, under some limitations, real-life maintenance environments and how the gradual adoption of prescriptive maintenance can improve efficiency. Both topics will be discussed in Section 4.

The scenarios also model the actual industry assembly line environment and evaluate the potential of substituting an expert maintenance engineer with an algorithm supported by Ecosystem 4.0. For example, actual robots' capabilities of drilling, MTBF, quantity, the maintenance schedule intervals and type, teams' size and skills, these are all parameters considered in the scenarios and the engineer's ability to prescribe the best team for a particular maintenance task.

\subsubsection{Scenario 1: Man-Hour Expertise Considered Constant}

Case 1 uses the formulation presented previously to simulate an experienced maintenance planner with knowledge of available teams to reduce maintenance downtimes. By doing this, the best team is prescribed for each maintenance activity. However, this case does not consider any evolution of team skills in the lifetime of the robots.

The SPMF algorithm can read the scheduled maintenance that has to be performed in period $i$, on equipment $r$, and select the best maintenance team based on its expertise (constant for the life-cycle considered 15 years). Performance and quality are also regarded as constant, equal to 0.85 and 0.95 , respectively. Table 2 shows the results:

Table 2. Scenario 1 results

\begin{tabular}{ccccc}
\hline $\begin{array}{c}\text { Total Maintenance } \\
\text { Man-Hour (h) }\end{array}$ & Cancelled Tasks & Total Downtime (h) & Availability & OEE \\
\hline 9676.5 & 19 & $11,804.50$ & $86.49 \%$ & $69.84 \%$ \\
\hline
\end{tabular}


3.2.2. Scenario 2: Man-Hour Expertise Considered Constant and Randomized Team Assignment

In this simulation, SPMF can read the scheduled maintenance that has to be performed in period $i$, on equipment $r$, but does not select the best maintenance team based on its expertise. It is the scenario in which team expertise is unknown. Thus, the teams are assigned randomly; therefore, the formulation presented previously is not used to solve this case differently from the other ones. Performance and quality are again considered constant, equal to 0.85 and 0.95 , respectively. Results are presented in Table 3:

Table 3. Scenario 2 results.

\begin{tabular}{ccccc}
\hline $\begin{array}{c}\text { Total Maintenance } \\
\text { Man-Hour (h) }\end{array}$ & Cancelled Tasks & Total Downtime (h) & Availability & OEE \\
\hline 10,868 & 19 & 12,996 & $85.12 \%$ & $68.74 \%$ \\
\hline
\end{tabular}

\subsubsection{Scenario 3: Man-Hour Expertise Considered Variable}

In this simulation, the SPMF algorithm plans the preventive maintenance, which has to be performed in period $i$, on equipment $r$, and selects the best maintenance team based on its expertise, which is now considered variable. In other words, the specialization of labour is simulated due to practice over the years. As proof of concept, it is assumed that expertise levels are updated yearly through machine learning. This assumption can be later altered by an ecosystem 4.0 that can monitor real-time expertise through sensors and algorithms that can track and evaluate individual performance directly or indirectly by monitoring equipment OEE. Table 4 shows the results:

Table 4. Scenario 3 results

\begin{tabular}{ccccc}
\hline $\begin{array}{c}\text { Total Maintenance } \\
\text { Man-Hour (h) }\end{array}$ & Cancelled Tasks & Total Downtime (h) & Availability & OEE \\
\hline 8153.8 & 19 & $10,281.8$ & $88.23 \%$ & $71.25 \%$ \\
\hline
\end{tabular}

3.2.4. Scenario 4: Man-Hour Expertise Considered Variable and Tasks Rescheduling

This case study adds to the SPMF algorithm the capability of maintenance task rescheduling on top of team assignment based on variable expertise. It is assumed that the information about the tasks, robots, and teams is provided in real-time by the IoT infrastructure. Here, the possibility of anticipating maintenance activities that were cancelled due to insufficient labour is presented in an attempt to reduce downtime further. Table 5 shows the results:

Table 5. Scenario 4 results

\begin{tabular}{ccccc}
\hline $\begin{array}{c}\text { Total Maintenance } \\
\text { Man-Hour (h) }\end{array}$ & Cancelled Tasks & Total Downtime (h) & Availability & OEE \\
\hline 8426.1 & 15 & $10,106.1$ & $88.43 \%$ & $71.41 \%$ \\
\hline
\end{tabular}

\section{Discussion}

Comparing the simulations and assuming a similar utilisation date for all the robots, a convergence was observed in the number of heavy maintenance tasks. It resulted in the optimisation of the maintenance process. This finding denoted that only an increase in working hours (or maintenance man-hours), achievable primarily by increasing the team size, could decrease the cancelled tasks. This hypothesis was tested in scenario 4: as shown in Figure 3, the team size was increased until the point that no tasks were cancelled, and, as a result, higher robots' availability and OEE were obtained. 


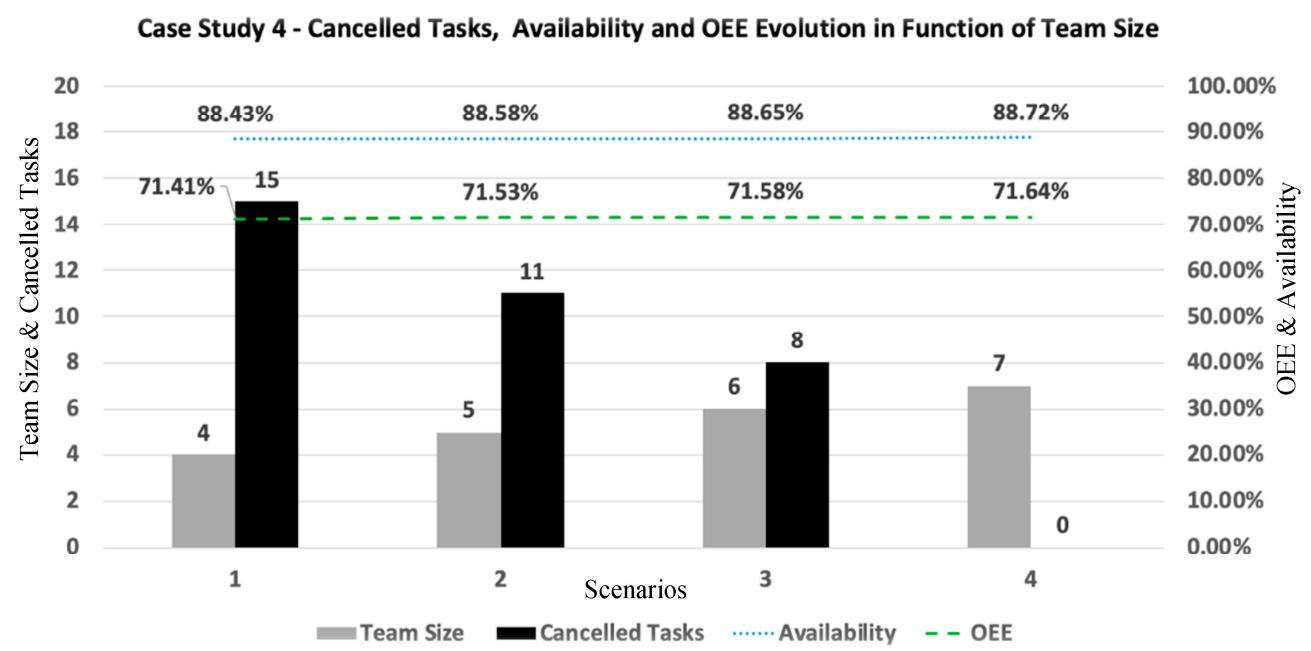

Figure 3. Case Study 4-Cancelled tasks, availability, and OEE evolution in team size function.

The study was limited by the following assumptions:

- No corrective maintenance was considered;

- Robots remaining useful life and degradation curve were not modelled; and

- Production demand, product quality, and robots' MTBF were considered constant.

It meant that the performance of the supporting capability of a complex system at its end of life-cycle, when more corrective maintenance takes place, or scheduled maintenance is anticipated, could not be assessed. As mentioned in the conclusion, future work will expand the simulation up to the inclusion of such situations.

Comparing the OEE and the availability obtained in each simulation, it was observed that the best results were obtained in the fourth scenario, as expected, since it featured not only assignments according to teams' expertise and increasing expertise over time, but also task rescheduling. The second scenario, characterized by randomized teams' assignment and constant expertise, presented the lowest OEE overall, confirming that not considering workforce skills in maintenance tasks' assignment is not a good strategy. Scenario 1, which considers workforce skills, presents improvements compared to scenario 1 , while scenario 3, which in addition to teams 'skills, considers skill improvements over time, as considered in the fourth scenario, further improves the results obtained in scenario 1. Figure 4 summarizes the comparisons of the results.

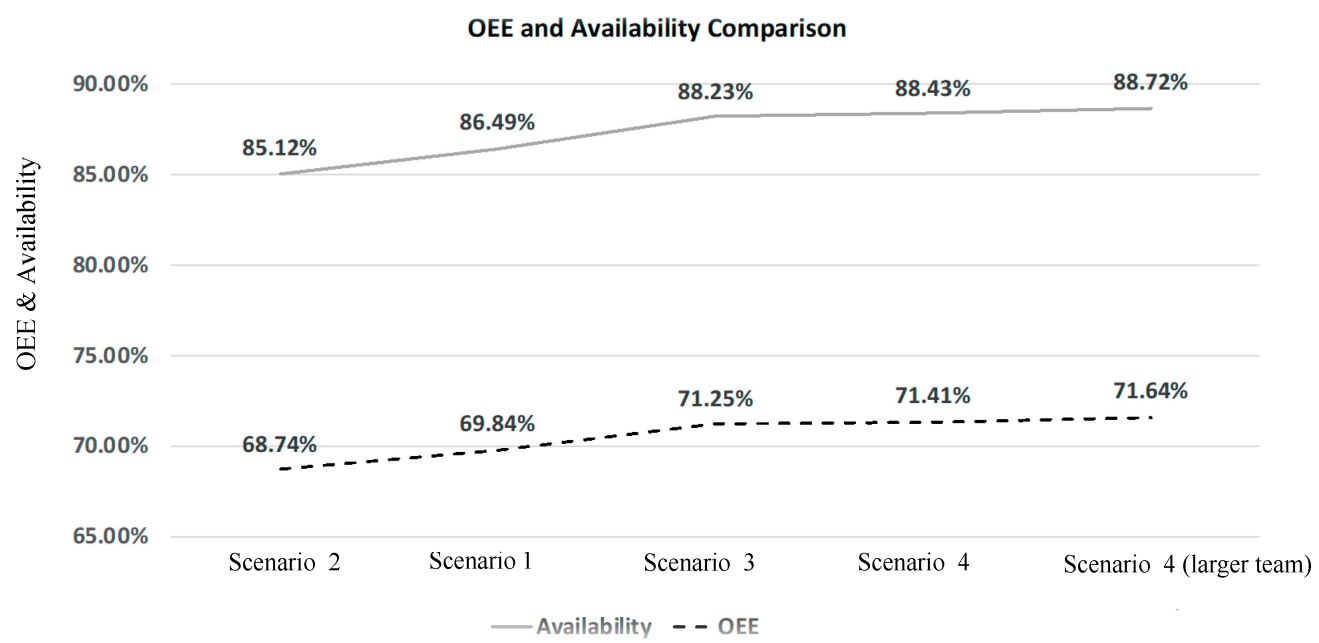

Figure 4. OEE and availability comparison among simulations. 


\section{Conclusions}

The paper tests the existing concepts of the SPMF for introducing prescriptive maintenance policy in an aviation assembly line composed of operators and 55 robots, 36 of which presented 25-year preventive maintenance plans and smart monitoring possibilities. Four different scenarios, characterised by different combination of man-hour expertise, team assignment and task rescheduling, were considered. This approached allowed identifying the most efficient situation to adopt. In the first simulation, the case study focused on assigning the best team to complete the maintenance task relative to a specific robot type in the scheduled interval. In the second case study, teams were randomly assigned to perform the maintenance tasks. The third simulation expertise was assumed variable, and the SPMF algorithm capable again of assigning the best team. The fourth study case focused on assigning the best team in a scenario of variable expertise and smart rescheduling maintenance. It was recognized as the most efficient with the highest OEE and lowest cancelled maintenance tasks due to unavailable labour.

Analysing each simulation result, it was observed that the number of tasks that could not be performed (cancelled tasks) was converging, indicating that, assuming a similar usage starting date for all the robots, maintenance rescheduling was not accurate enough to avoid cancelled tasks without increasing the size of the maintenance team.

The results demonstrated that the SPMF concepts' effectiveness helped the maintenance specialist decision in an Ecosystem 4.0 supported assembly line, reducing the human effort for maintenance schedule significantly.

Future work will focus on expanding the simulation model to include equipment degradation and RUL as triggers for maintenance (condition-based maintenance), different equipment usage start date, tooling and materials availability, product demand, robots' MTBF and quality variability, as well as "tribal" knowledge and historical maintenance data as sources of lessons learned to improve the algorithm.

Author Contributions: Conceptualization, H.C.M. and A.G.; formal analysis, E.A.P.B.; methodology, A.G. and E.A.P.B.; software, A.G. and E.A.P.B.; writing-original draft preparation, H.C.M.; writing-review and editing, A.M.; All authors have read and agreed to the published version of the manuscript.

Funding: This study was financed in part by the Coordenação de Aperfeiçoamento de Pessoal de Nivel Superior-Brazil (CAPES)_Finance Code 001.

Institutional Review Board Statement: Not applicable.

Informed Consent Statement: Not applicable.

Data Availability Statement: Not applicable.

Conflicts of Interest: The authors declare no conflict of interest.

$\begin{array}{ll}\text { Abbreviations } \\ \text { CBM } & \text { Condition-Based Maintenance } \\ \text { CMP } & \text { Cyclic Maintenance } \\ \text { IIoT } & \text { Industrial Internet of Things } \\ \text { MIP } & \text { Mixed Integer Programming } \\ \text { MTBF } & \text { Meantime Between Failures } \\ \text { MTTR } & \text { Meantime to Repair } \\ \text { NCMP } & \text { Non-Cyclic Maintenance } \\ \text { OEE } & \text { Overall Equipment Effectiveness } \\ \text { RAMS } & \text { Reliability, Availability, Maintainability, and Safety } \\ \text { RUL } & \text { Remaining Useful Life } \\ \text { SPMF } & \text { Smart Prescriptive Maintenance Framework } \\ \text { TPM } & \text { Total Productive Maintenance }\end{array}$




\section{Appendix A}

Appendix A presents the tables containing the number of rivets considered in the assembly line and the study case parameters for all 55 machines considered.

Table A2 shows the parameters of the assembly line described in Section 3.1. The columns description follows:

- 1 1st column: the equipment was modelled in 12 different robot types distributed in 42 production cells along with 13 cells equipped with human labour and tools;

- $\quad$ 2nd column: it lists the assembly level according to the description of Section 3.1;

- 3rd column: it presents the riveting capacity per wing. It is essential to add that the monthly wing demand was considered equal to 43;

- 4th column: the MTBF was identified for each robot type;

- 5th column: here the production rate, in riveting per minute, was defined for each robot according to the information collected during the interviews and the literature review, as described in Table 1;

- 6th column: for each piece of equipment, a maintenance class was selected. According to Gopalakrishnan [24], Class A represents the assembly line's most important robots, which, in turn, receive the most resources and more sophisticated maintenance strategies in an attempt to minimize downtime since an inactive Class A robot is highly uneconomic for management. Class B equipment is less critical than Class A but more fundamental than Class C. Usually, Class B equipment receives fewer resources than Class A but is still within the equipment set that presents a maintenance strategy that aims to minimize downtime preventive maintenance. Class $C$ robots usually do not receive any resources to prevent unforeseen failures since downtime is economically acceptable for this equipment class. Being less costly than Class A and B, often these Class $C$ equipment are substituted upon failure by the maintenance team;

- 7th column: as a function of the class, a maintenance strategy is assigned to each robot. Total Production Maintenance (TPM) combined with Condition Based Maintenance (CBM) are some examples. The strategy can also be constituted only by TPM or just letting the equipment fail, that is, on condition;

- $\quad$ 8th-15th columns: the last eight columns list the four considered maintenance tasks, their respective intervals, and Mean Times to Repair (MTTR). 
Table A1. Number of rivets/fasteners for a three-piece wing [19].

\begin{tabular}{|c|c|c|c|c|c|c|c|c|}
\hline \multirow[t]{2}{*}{ Assembly Level } & \multirow[t]{2}{*}{$\begin{array}{l}\text { Assembly } \\
\text { Strategy }\end{array}$} & \multirow[t]{2}{*}{ Structural Component } & \multicolumn{6}{|c|}{ Number of Rivets/Fasteners per Joining Operation } \\
\hline & & & $\begin{array}{l}\text { Stringer/Caps to } \\
\text { Skin/Web }\end{array}$ & Stiffeners to Web & $\begin{array}{c}\text { Shear \& Butterflies/Clips } \\
\text { to Skins and Stringers }\end{array}$ & $\begin{array}{l}\text { Spar Caps to } \\
\text { Panels }\end{array}$ & Box to Box & Total \\
\hline 1st Level & Robot & $\begin{array}{c}\text { Panels } \\
\text { Spars Ribs/Bulkhead }\end{array}$ & $\begin{array}{l}24.300 \\
14.400\end{array}$ & $\begin{array}{l}7.800 \\
1.400\end{array}$ & & & & 60.500 \\
\hline 2nd Level & Human + Tool & $\begin{array}{l}\text { Ribs/Bulkhead/Spars- } \\
\text { Grid }\end{array}$ & & 6.000 & & & & 6000 \\
\hline 4th Level & Robot & & & & & & 2700 & 2700 \\
\hline & & Total & 38.700 & 27,800 & 20,300 & 16,200 & 2700 & 105,700 \\
\hline
\end{tabular}

Table A2. Assembly Line Model Parameters.

\begin{tabular}{|c|c|c|c|c|c|c|c|c|c|c|c|c|c|c|}
\hline \multirow{3}{*}{ Robot } & \multirow{3}{*}{$\begin{array}{c}\text { Assembly } \\
\text { Level }\end{array}$} & \multirow{3}{*}{$\begin{array}{l}\mathrm{d}_{\mathrm{i}} \text { (Rivet- } \\
\text { ing/Wing) }\end{array}$} & \multirow{3}{*}{ MTBF (hs) } & \multirow{3}{*}{$\begin{array}{l}\text { Production } \\
\text { Rate (Rivet- } \\
\text { ing/Minute) }\end{array}$} & \multirow{3}{*}{$\begin{array}{l}\text { Maint. } \\
\text { Class }\end{array}$} & \multirow{3}{*}{$\begin{array}{l}\text { Maint. } \\
\text { Strategy }\end{array}$} & \multicolumn{8}{|c|}{ Maintenance Task } \\
\hline & & & & & & & \multicolumn{2}{|c|}{ Visual Inspection } & \multicolumn{2}{|c|}{ Battery Servicing } & \multicolumn{2}{|c|}{ Overhaul } & \multicolumn{2}{|c|}{ Refurbishment } \\
\hline & & & & & & & $\begin{array}{c}\text { Interval } \\
\text { (Week) }\end{array}$ & $\begin{array}{c}\text { MTTR } \\
\text { (hs) }\end{array}$ & $\begin{array}{l}\text { Interval } \\
\text { (Month) }\end{array}$ & $\begin{array}{c}\text { MTTR } \\
\text { (hs) }\end{array}$ & $\begin{array}{l}\text { Interval } \\
\text { (Month) }\end{array}$ & $\underset{\text { (hs) }}{\text { MTTR }}$ & $\begin{array}{c}\text { Interval } \\
\text { (Years) }\end{array}$ & $\begin{array}{c}\text { MTTR } \\
\text { (hs) }\end{array}$ \\
\hline Robot Type 1 & 1st level & 10,084 & 570 & 10 & Class A & $\mathrm{TPM}+\mathrm{CBM}$ & weekly & 0.1833 & 12 & 2 & 36 & 12 & 120 & 96 \\
\hline Robot Type 2 & 1st level & 10,084 & 370 & 10 & Class B & TPM & weekly & 0.1833 & 13 & 2 & 48 & 12 & 170 & 96 \\
\hline Robot Type 3 & 1st level & 10,083 & 470 & 10 & Class B & TPM & weekly & 0.1833 & 12 & 2 & 50 & 12 & 180 & 96 \\
\hline Robot Type 1 & 1st level & 10,083 & 570 & 10 & Class B & TPM & weekly & 0.1833 & 12 & 2 & 36 & 12 & 120 & 96 \\
\hline Robot Type 2 & 1st level & 10,083 & 370 & 10 & Class B & TPM & weekly & 0.1833 & 13 & 2 & 48 & 12 & 170 & 96 \\
\hline Robot Type 3 & 1st level & 10,083 & 470 & 10 & Class B & TPM & weekly & 0.1833 & 12 & 2 & 50 & 12 & 180 & 96 \\
\hline Human + Tool & 2nd level & 465 & 501 & 0.5 & Class $\mathrm{C}$ & On Condition & $\mathrm{N} / \mathrm{A}$ & $\mathrm{N} / \mathrm{A}$ & $\mathrm{N} / \mathrm{A}$ & $\mathrm{N} / \mathrm{A}$ & $\mathrm{N} / \mathrm{A}$ & $\mathrm{N} / \mathrm{A}$ & $\mathrm{N} / \mathrm{A}$ & N/A \\
\hline Human + Tool & 2nd level & 465 & 501 & 0.5 & Class C & On Condition & N/A & N/A & N/A & N/A & N/A & $\mathrm{N} / \mathrm{A}$ & N/A & N/A \\
\hline Human + Tool & 2nd level & 465 & 501 & 0.5 & Class $\mathrm{C}$ & On Condition & $\mathrm{N} / \mathrm{A}$ & N/A & $\mathrm{N} / \mathrm{A}$ & $\mathrm{N} / \mathrm{A}$ & $\mathrm{N} / \mathrm{A}$ & $\mathrm{N} / \mathrm{A}$ & $\mathrm{N} / \mathrm{A}$ & N/A \\
\hline Human + Tool & 2nd level & 465 & 501 & 0.5 & Class C & On Condition & N/A & N/A & N/A & N/A & N/A & $\mathrm{N} / \mathrm{A}$ & N/A & N/A \\
\hline Human + Tool & 2nd level & 460 & 501 & 0.5 & Class C & On Condition & N/A & N/A & $\mathrm{N} / \mathrm{A}$ & N/A & $\mathrm{N} / \mathrm{A}$ & $\mathrm{N} / \mathrm{A}$ & N/A & N/A \\
\hline Human + Tool & 2nd level & 460 & 501 & 0.5 & Class C & On Condition & N/A & N/A & N/A & N/A & $\mathrm{N} / \mathrm{A}$ & N/A & N/A & N/A \\
\hline Human + Tool & 2nd level & 460 & 501 & 0.5 & Class C & On Condition & $\mathrm{N} / \mathrm{A}$ & $\mathrm{N} / \mathrm{A}$ & $\mathrm{N} / \mathrm{A}$ & $\mathrm{N} / \mathrm{A}$ & $\mathrm{N} / \mathrm{A}$ & $\mathrm{N} / \mathrm{A}$ & $\mathrm{N} / \mathrm{A}$ & N/A \\
\hline
\end{tabular}


Table A2. Cont.

\begin{tabular}{|c|c|c|c|c|c|c|c|c|c|c|c|c|c|c|}
\hline \multirow{3}{*}{ Robot } & \multirow{3}{*}{$\begin{array}{c}\text { Assembly } \\
\text { Level }\end{array}$} & \multirow{3}{*}{$\begin{array}{l}d_{i} \text { (Rivet- } \\
\text { ing/Wing) }\end{array}$} & \multirow{3}{*}{ MTBF (hs) } & \multirow{3}{*}{$\begin{array}{l}\text { Production } \\
\text { Rate (Rivet- } \\
\text { ing/Minute) }\end{array}$} & \multirow{3}{*}{$\begin{array}{l}\text { Maint. } \\
\text { Class }\end{array}$} & \multirow{3}{*}{$\begin{array}{c}\text { Maint. } \\
\text { Strategy }\end{array}$} & \multicolumn{8}{|c|}{ Maintenance Task } \\
\hline & & & & & & & \multicolumn{2}{|c|}{ Visual Inspection } & \multicolumn{2}{|c|}{ Battery Servicing } & \multicolumn{2}{|c|}{ Overhaul } & \multicolumn{2}{|c|}{ Refurbishment } \\
\hline & & & & & & & $\begin{array}{c}\text { Interval } \\
\text { (Week) }\end{array}$ & $\begin{array}{c}\text { MTTR } \\
\text { (hs) }\end{array}$ & $\begin{array}{l}\text { Interval } \\
\text { (Month) }\end{array}$ & $\begin{array}{c}\text { MTTR } \\
\text { (hs) }\end{array}$ & $\begin{array}{l}\text { Interval } \\
\text { (Month) }\end{array}$ & $\begin{array}{c}\text { MTTR } \\
\text { (hs) }\end{array}$ & $\begin{array}{c}\text { Interval } \\
\text { (Years) }\end{array}$ & $\begin{array}{c}\text { MTTR } \\
\text { (hs) }\end{array}$ \\
\hline Human + Tool & 2nd level & 460 & 501 & 0.5 & Class C & On Condition & $\mathrm{N} / \mathrm{A}$ & $\mathrm{N} / \mathrm{A}$ & $\mathrm{N} / \mathrm{A}$ & $\mathrm{N} / \mathrm{A}$ & N/A & $\mathrm{N} / \mathrm{A}$ & $\mathrm{N} / \mathrm{A}$ & $\mathrm{N} / \mathrm{A}$ \\
\hline Human + Tool & 2nd level & 460 & 501 & 0.5 & Class C & On Condition & $\mathrm{N} / \mathrm{A}$ & $\mathrm{N} / \mathrm{A}$ & $\mathrm{N} / \mathrm{A}$ & $\mathrm{N} / \mathrm{A}$ & $\mathrm{N} / \mathrm{A}$ & $\mathrm{N} / \mathrm{A}$ & $\mathrm{N} / \mathrm{A}$ & N/A \\
\hline Human + Tool & 2nd level & 460 & 501 & 0.5 & Class C & On Condition & $\mathrm{N} / \mathrm{A}$ & $\mathrm{N} / \mathrm{A}$ & $\mathrm{N} / \mathrm{A}$ & $\mathrm{N} / \mathrm{A}$ & $\mathrm{N} / \mathrm{A}$ & $\mathrm{N} / \mathrm{A}$ & $\mathrm{N} / \mathrm{A}$ & $\mathrm{N} / \mathrm{A}$ \\
\hline Human + Tool & 2nd level & 460 & 501 & 0.5 & Class C & On Condition & $\mathrm{N} / \mathrm{A}$ & $\mathrm{N} / \mathrm{A}$ & $\mathrm{N} / \mathrm{A}$ & $\mathrm{N} / \mathrm{A}$ & $\mathrm{N} / \mathrm{A}$ & $\mathrm{N} / \mathrm{A}$ & N/A & N/A \\
\hline Human + Tool & 2nd level & 460 & 501 & 0.5 & Class $\mathrm{C}$ & On Condition & N/A & N/A & $\mathrm{N} / \mathrm{A}$ & $\mathrm{N} / \mathrm{A}$ & $\mathrm{N} / \mathrm{A}$ & $\mathrm{N} / \mathrm{A}$ & $\mathrm{N} / \mathrm{A}$ & $\mathrm{N} / \mathrm{A}$ \\
\hline Robot Type 1 & 3rd level & 1141 & 570 & 1.2 & Class B & TPM & weekly & 0.1833 & 12 & 2 & 36 & 12 & 120 & 96 \\
\hline Robot Type 2 & 3rd level & 1141 & 370 & 1.2 & Class B & TPM & weekly & 0.1833 & 13 & 2 & 48 & 12 & 170 & 96 \\
\hline Robot Type 3 & 3rd level & 1141 & 470 & 1.2 & Class B & TPM & weekly & 0.1833 & 12 & 2 & 50 & 12 & 180 & 96 \\
\hline Robot Type 4 & 3rd level & 1141 & 430 & 1.2 & Class B & TPM & weekly & 0.1833 & 12 & 2 & 53 & 12 & 171 & 96 \\
\hline Robot Type 5 & 3rd level & 1141 & 400 & 1.2 & Class B & TPM & weekly & 0.1833 & 14 & 2 & 37 & 12 & 180 & 96 \\
\hline Robot Type 6 & 3rd level & 1141 & 440 & 1.2 & Class B & TPM & weekly & 0.1833 & 12 & 2 & 41 & 12 & 173 & 96 \\
\hline Robot Type 7 & 3rd level & 1141 & 510 & 1.2 & Class B & TPM & weekly & 0.1833 & 12 & 2 & 39 & 12 & 138 & 96 \\
\hline Robot Type 9 & 3rd level & 1141 & 319 & 1.2 & Class B & TPM & weekly & 0.1833 & 12 & 2 & 51 & 12 & 180 & 96 \\
\hline Robot Type 10 & 3rd level & 1141 & 289 & 1.2 & Class B & TPM & weekly & 0.1833 & 12 & 2 & 41 & 12 & 132 & 96 \\
\hline Robot Type 1 & 3rd level & 1141 & 570 & 1.2 & Class B & TPM & weekly & 0.1833 & 12 & 2 & 36 & 12 & 120 & 96 \\
\hline Robot Type 2 & 3rd level & 1141 & 370 & 1.2 & Class B & TPM & weekly & 0.1833 & 13 & 2 & 48 & 12 & 170 & 96 \\
\hline Robot Type 3 & 3rd level & 1141 & 470 & 1.2 & Class B & TPM & weekly & 0.1833 & 12 & 2 & 50 & 12 & 180 & 96 \\
\hline Robot Type 4 & 3rd level & 1141 & 430 & 1.2 & Class B & TPM & weekly & 0.1833 & 12 & 2 & 53 & 12 & 171 & 96 \\
\hline Robot Type 5 & 3rd level & 1141 & 400 & 1.2 & Class B & TPM & weekly & 0.1833 & 14 & 2 & 37 & 12 & 180 & 96 \\
\hline Robot Type 6 & 3rd level & 1141 & 440 & 1.2 & Class B & TPM & weekly & 0.1833 & 12 & 2 & 41 & 12 & 173 & 96 \\
\hline Robot Type 7 & 3rd level & 1141 & 510 & 1.2 & Class B & TPM & weekly & 0.1833 & 12 & 2 & 39 & 12 & 138 & 96 \\
\hline Robot Type 8 & 3rd level & 1141 & 517 & 1.2 & Class B & TPM & weekly & 0.1833 & 11 & 2 & 53 & 12 & 123 & 96 \\
\hline Robot Type 9 & 3rd level & 1141 & 319 & 1.2 & Class B & TPM & weekly & 0.1833 & 12 & 2 & 51 & 12 & 180 & 96 \\
\hline Robot Type 10 & 3rd level & 1141 & 289 & 1.2 & Class B & TPM & weekly & 0.1833 & 12 & 2 & 41 & 12 & 132 & 96 \\
\hline Robot Type 1 & 3rd level & 1140 & 570 & 1.2 & Class B & TPM & weekly & 0.1833 & 12 & 2 & 36 & 12 & 120 & 96 \\
\hline Robot Type 2 & 3rd level & 1140 & 370 & 1.2 & Class B & TPM & weekly & 0.1833 & 13 & 2 & 48 & 12 & 170 & 96 \\
\hline
\end{tabular}


Table A2. Cont.

\begin{tabular}{|c|c|c|c|c|c|c|c|c|c|c|c|c|c|c|}
\hline \multirow{3}{*}{ Robot } & \multirow{3}{*}{$\begin{array}{c}\text { Assembly } \\
\text { Level }\end{array}$} & \multirow{3}{*}{$\begin{array}{l}d_{i} \text { (Rivet- } \\
\text { ing/Wing) }\end{array}$} & \multirow{3}{*}{ MTBF (hs) } & \multirow{3}{*}{$\begin{array}{l}\text { Production } \\
\text { Rate (Rivet- } \\
\text { ing/Minute) }\end{array}$} & \multirow{3}{*}{$\begin{array}{l}\text { Maint. } \\
\text { Class }\end{array}$} & \multirow{3}{*}{$\begin{array}{l}\text { Maint. } \\
\text { Strategy }\end{array}$} & \multicolumn{8}{|c|}{ Maintenance Task } \\
\hline & & & & & & & \multicolumn{2}{|c|}{ Visual Inspection } & \multicolumn{2}{|c|}{ Battery Servicing } & \multicolumn{2}{|c|}{ Overhaul } & \multicolumn{2}{|c|}{ Refurbishment } \\
\hline & & & & & & & $\begin{array}{c}\text { Interval } \\
\text { (Week) }\end{array}$ & $\underset{\text { (hs) }}{\text { MTTR }}$ & $\begin{array}{l}\text { Interval } \\
\text { (Month) }\end{array}$ & $\underset{\text { (hs) }}{\text { MTTR }}$ & $\begin{array}{l}\text { Interval } \\
\text { (Month) }\end{array}$ & $\underset{\text { (hs) }}{\text { MTTR }}$ & $\begin{array}{c}\text { Interval } \\
\text { (Years) }\end{array}$ & $\begin{array}{c}\text { MTTR } \\
\text { (hs) }\end{array}$ \\
\hline Robot Type 4 & 3rd level & 1140 & 430 & 1.2 & Class B & TPM & weekly & 0.1833 & 12 & 2 & 53 & 12 & 171 & 96 \\
\hline Robot Type 5 & 3rd level & 1140 & 400 & 1.2 & Class B & TPM & weekly & 0.1833 & 14 & 2 & 37 & 12 & 180 & 96 \\
\hline Robot Type 6 & 3rd level & 1140 & 440 & 1.2 & Class C & On Condition & N/A & N/A & N/A & N/A & N/A & N/A & N/A & N/A \\
\hline Robot Type 7 & 3rd level & 1140 & 510 & 1.2 & Class C & On Condition & $\mathrm{N} / \mathrm{A}$ & $\mathrm{N} / \mathrm{A}$ & $\mathrm{N} / \mathrm{A}$ & $\mathrm{N} / \mathrm{A}$ & $\mathrm{N} / \mathrm{A}$ & $\mathrm{N} / \mathrm{A}$ & N/A & N/A \\
\hline Robot Type 8 & 3rd level & 1140 & 517 & 1.2 & Class $\mathrm{C}$ & On Condition & $\mathrm{N} / \mathrm{A}$ & $\mathrm{N} / \mathrm{A}$ & $\mathrm{N} / \mathrm{A}$ & $\mathrm{N} / \mathrm{A}$ & $\mathrm{N} / \mathrm{A}$ & $\mathrm{N} / \mathrm{A}$ & $\mathrm{N} / \mathrm{A}$ & $\mathrm{N} / \mathrm{A}$ \\
\hline Robot Type 9 & 3rd level & 1140 & 319 & 1.2 & Class C & On Condition & $\mathrm{N} / \mathrm{A}$ & $\mathrm{N} / \mathrm{A}$ & $\mathrm{N} / \mathrm{A}$ & $\mathrm{N} / \mathrm{A}$ & $\mathrm{N} / \mathrm{A}$ & $\mathrm{N} / \mathrm{A}$ & $\mathrm{N} / \mathrm{A}$ & N/A \\
\hline Robot Type 10 & 3rd level & 1140 & 289 & 1.2 & Class C & On Condition & $\mathrm{N} / \mathrm{A}$ & $\mathrm{N} / \mathrm{A}$ & $\mathrm{N} / \mathrm{A}$ & $\mathrm{N} / \mathrm{A}$ & $\mathrm{N} / \mathrm{A}$ & $\mathrm{N} / \mathrm{A}$ & $\mathrm{N} / \mathrm{A}$ & $\mathrm{N} / \mathrm{A}$ \\
\hline Robot Type 3 & 3rd level & 1140 & 470 & 1.2 & Class $\mathrm{C}$ & On Condition & $\mathrm{N} / \mathrm{A}$ & $\mathrm{N} / \mathrm{A}$ & N/A & $\mathrm{N} / \mathrm{A}$ & $\mathrm{N} / \mathrm{A}$ & $\mathrm{N} / \mathrm{A}$ & $\mathrm{N} / \mathrm{A}$ & $\mathrm{N} / \mathrm{A}$ \\
\hline Robot Type 4 & 3rd level & 1140 & 430 & 1.2 & Class A & $\mathrm{TPM}+\mathrm{CBM}$ & weekly & 0.1833 & 12 & 2 & 53 & 12 & 171 & 96 \\
\hline Robot Type 11 & 4th level & 675 & 489 & 1 & Class A & $\mathrm{TPM}+\mathrm{CBM}$ & weekly & 0.1833 & 10 & 2 & 48 & 12 & 144 & 96 \\
\hline Robot Type 11 & 4th level & 675 & 489 & 1 & Class A & $\mathrm{TPM}+\mathrm{CBM}$ & weekly & 0.1833 & 10 & 2 & 48 & 12 & 144 & 96 \\
\hline Robot Type 12 & 4th level & 675 & 511 & 1 & Class A & $\mathrm{TPM}+\mathrm{CBM}$ & weekly & 0.1833 & 12 & 2 & 39 & 12 & 151 & 96 \\
\hline Robot Type 12 & Total & 105,700 & & & & & & & & & & & & \\
\hline
\end{tabular}




\section{References}

1. Schoenberger, R. From Cars to Planes-Aerospace Manufacturing and Design. Available online: https://www.aerospacemanuf acturinganddesign.com/article/amd1114-aerospace-assembly-automation/ (accessed on 22 March 2021).

2. Bogue, R. The Growing Use of Robots by the Aerospace Industry. Ind. Robot Int. J. 2018, 45, 705-709. [CrossRef]

3. de Mello, J.M.G.; Trabasso, L.G.; Reckevcius, A.C.; Palmeira, A.L.O.A.; Reiss, P.; Caraca, W. A Novel Jigless Process Applied to a Robotic Cell for Aircraft Structural Assembly. Int. J. Adv. Manuf. Technol. 2020, 109, 1177-1187. [CrossRef]

4. Duffuaa, S.; Raouf, A. Planning and Control of Maintenance Systems: Modelling and Analysis, 2nd ed.; Springer International Publishing: Cham, Switzerland, 2015; ISBN 978-3-319-19802-6.

5. Qi, Q.; Tao, F.; Hu, T.; Anwer, N.; Liu, A.; Wei, Y.; Wang, L.; Nee, A.Y.C. Enabling Technologies and Tools for Digital Twin. J. Manuf. Syst. 2019. [CrossRef]

6. He, B.; Bai, K.-J. Digital Twin-Based Sustainable Intelligent Manufacturing: A Review. Adv. Manuf. 2020. [CrossRef]

7. Gao, R.X.; Wang, L.; Helu, M.; Teti, R. Big Data Analytics for Smart Factories of the Future. CIRP Ann. 2020, 69, 668-692. [CrossRef]

8. Choubey, S.; Benton, R.G.; Johnsten, T. A Holistic End-to-End Prescriptive Maintenance Framework. Data-Enabled Discov. Appl. 2021, 4, 11. [CrossRef]

9. Marques, H.; Giacotto, A. Prescriptive Maintenance: Building Alternative Plans for Smart Operations; Swedish Society of Aeronautics and Astronautics (FTF): Stockholm, Sweden, 2019; pp. 231-236.

10. Shamsaei, F.; Van Vyve, M. Solving Integrated Production and Condition-Based Maintenance Planning Problems by MIP Modeling. Flex. Serv. Manuf. J. 2017, 29, 184-202. [CrossRef]

11. Matyas, K.; Nemeth, T.; Kovacs, K.; Glawar, R. A Procedural Approach for Realizing Prescriptive Maintenance Planning in Manufacturing Industries. CIRP Ann. 2017, 66, 461-464. [CrossRef]

12. Koops, L.G. Optimized Maintenance Decision-Making-A Simulation-Supported Prescriptive Analytics Approach Based on Probabilistic Cost-Benefit Analysis. PHM Soc. Eur. Conf. 2020, 5, 14. [CrossRef]

13. Kerin, M.; Pham, D.T. Smart Remanufacturing: A Review and Research Framework. J. Manuf. Technol. Manag. 2020, $31,1205-1235$. [CrossRef]

14. Navas, M.A.; Sancho, C.; Carpio, J. Disruptive Maintenance Engineering 4.0. Int. J. Qual. Reliab. Manag. 2020, 37, 853-871. [CrossRef]

15. Munín-Doce, A.; Díaz-Casás, V.; Trueba, P.; Ferreno-González, S.; Vilar-Montesinos, M. Industrial Internet of Things in the Production Environment of a Shipyard 4.0. Int. J. Adv. Manuf. Technol. 2020, 108, 47-59. [CrossRef]

16. Diez-Olivan, A.; Del Ser, J.; Galar, D.; Sierra, B. Data Fusion and Machine Learning for Industrial Prognosis: Trends and Perspectives towards Industry 4.0. Inf. Fusion 2019, 50, 92-111. [CrossRef]

17. Chang, H.-M.; Huang, C.; Torng, C.-C. Lean Production Implement Model for Aerospace Manufacturing Suppliers. Int. J. Innov. Manag. Technol. 2013. [CrossRef]

18. Schrotenboer, A.H.; Ursavas, E.; Vis, I.F.A. Mixed Integer Programming Models for Planning Maintenance at Offshore Wind Farms under Uncertainty. Transp. Res. Part C Emerg. Technol. 2020, 112, 180-202. [CrossRef]

19. Sarh, B. Wing Structural Assembly Methodology; SAE International: Long Beach, CA, USA, 1998; p. 982156.

20. Kampa, A.; Gołda, G.; Paprocka, I. Discrete Event Simulation Method as a Tool for Improvement of Manufacturing Systems. Computers 2017, 6, 10. [CrossRef]

21. Kampa, A. The Review of Reliability Factors Related to Industrial Robo. Robot. Autom. Eng. J. 2018, 3. [CrossRef]

22. Dhillon, B.S.; Yang, N. Reliability Analysis of a Repairable Robot System. J. Qual. Maint. Eng. 1996, 2, 30-37. [CrossRef]

23. Dhillon, B.S.; Aleem, M.A. A Report on Robot Reliability and Safety in Canada: A Survey of Robot Users. J. Qual. Maint. Eng. 2000, 6, 61-74. [CrossRef]

24. Gopalakrishnan, M.; Skoogh, A. Machine Criticality Based Maintenance Prioritization: Identifying Productivity Improvement Potential. Int. J. Product. Perform. Manag. 2018, 67, 654-672. [CrossRef]

25. Khatab, A.; Diallo, C.; Venkatadri, U.; Liu, Z.; Aghezzaf, E.-H. Optimization of the Joint Selective Maintenance and Repairperson Assignment Problem under Imperfect Maintenance. Comput. Ind. Eng. 2018, 125, 413-422. [CrossRef]

26. ILO Benchmarking of Qualifications Frameworks: A Report on Potential Comparability between the Bangladesh Technical and Vocational Qualifications Framework and Qualifications Frameworks of Other Countries of Origin and Destination of Migrant Workers-Skills and Employability Network. Available online: http://apskills.ilo.org/resources/benchmarking-of-qualificatio ns-frameworks-a-report-on-potential-comparability-between-the-bangladesh-technical-and-vocational-qualifications-frame work-and-qualifications-frameworks-of-other-countries-of-origin-and-destination-of-migrant-workers (accessed on $11 \mathrm{March}$ 2021).

27. Apple MacOS Big Sur. Available online: https://www.apple.com/macos/big-sur/ (accessed on 11 March 2021).

28. Gurobi Software Downloads and License Center. Available online: https://www.gurobi.com/downloads/ (accessed on 11 March 2021).

29. Mathworks MATLAB \& Simulink. Available online: https://www.mathworks.com/products/matlab.html (accessed on 11 March 2021). 